\title{
Efficacy of Cloth Face Mask in Reducing COVID-19 Trans- mission: A Literature Review
}

\author{
Saraswati Anindita Rizki ${ }^{1}$, Andree Kurniawan ${ }^{2 *}$
}

${ }^{1}$ Faculty of Medicine, Pelita Harapan University, Indonesia

${ }^{2}$ Department of Internal Medicine, Faculty of Medicine, Pelita Harapan University, Indonesia

\begin{abstract}
Coronavirus disease 2019 (COVID-19) has become a public health concern. Preventive measures, such as wearing personal protective equipment, must be done. On April 2020, the Center for Disease Control stated cloth face mask was recommended to be used by the public. This systematic review aimed to evaluate the efficacy of cloth face masks in reducing COVID-19 transmission and to compare the fabric material that suits best for a cloth face mask. Journals included were from databases such as Google Scholar, PubMed, search engines, and references from other studies. The MeSH keywords, such as "cloth mask efficiency", "surgical mask", "COVID-19" and "filtration performance of common fabrics cloth mask" were used. Studies that used particle microorganisms sized $\leq 0.072 \mu \mathrm{m}$ were included in this study. Studies showed that cloth face mask still can filter to a certain extent, however, it is inferior compared to surgical mask. Results show that the efficacy of cloth face mask depends on its fabric, and that polyester provides the best filtration efficiency. However, the pressure drop of polyester is unknown and more studies should be done.
\end{abstract}

Keywords: cloth face mask, COVID-19, efficacy, face mask, surgical mask

\section{Introduction}

Coronavirus disease 2019 (COVID-19) is a disease caused by the novel coronavirus SARS-CoV-2, which initially spread in Wuhan, China. The World Health Organization (WHO) declared COVID-19 a public health emergency of international concern in January 2020. The disease has now become a pandemic with 5,406,282 COVID-19 confirmed cases globally and 23,165 COVID-19 confirmed cases in Indonesia. ${ }^{1}$ Its case fatality rate (CFR) has been dynamically changing, however as per May 2020, the CFR reported globally is $6.35 \%$ and the CFR reported in Indonesia is as high as $6.1 \%$. The SARS-CoV-2's infectiousness has become a public health concern. ${ }^{1}$

WHO stated that SARS-CoV-2 is transmitted primarily through droplets. Direct contact with objects contaminated by the virus and then touching the face may also be another mode of transmission. Airborne transmission of SARS-CoV-2 only occurs in clinical settings, where aerosol-generating procedures are done. These procedures include endotracheal intubation, manual ventilation before performing intubation, performing cardiopulmonary resuscitation (CPR), and administering

Correspondence*: Andree Kurniawan, Department of Internal Medicine, Faculty of Medicine, Pelita Harapan University, Jend. Sudirman Street No.20, Tangerang, Banten, Indonesia, E-mail: andree.kurniawan@uph.edu, Phone: +62-2154010130 treatment using a nebulizer. ${ }^{2}$ Recent studies showed that COVID-19 patients who appear asymptomatic or presymptomatic may be infectious.

This information raised the significance of using personal protective equipment (PPE), such as face masks. Although research regarding the efficacy of public maskwearing is scarce, some countries, such as Indonesia, the Czech Republic, Slovakia, and Germany proceed with public mask-wearing policies. A cross-sectional study in Hongkong concluded the indirect efficacy of public mask-wearing. This was shown by the reduction of influenza cases in Hong Kong after public mask-wearing policy, which aimed to reduce COVID-19 transmission, was implemented. ${ }^{3}$

In April 3, 2020, the Centers for Disease Control and Prevention (CDC) recommended the use of cloth face masks in public settings where physical distancing was difficult to conduct. ${ }^{4}$ This study aims to evaluate the efficacy of cloth face mask in reducing COVID-19 transmission and to compare the efficacy of common fabrics.

\section{Method}

A literature search was conducted on April $5-20^{\text {th }}$,

Received : May 27, 2020

Accepted : May 28, 2020

Published: July 31, 2020 
2020. A literature search process was continued using the limits of the literature research and then the titles were selected from each database followed the PICO framework, using combined terms and Medical Subject Headings of the National Library of Medicine (MeSH). Journals included were from databases, such as Google Scholar and PubMed, using a combination of keywords MeSH "cloth mask efficiency", "COVID-19", "surgical mask" and "filtration performance of common fabrics cloth mask". Some journals were from search engines and references from other journals. Studies evaluated the efficacy of cloth masks in the COVID-19 era were included. Other language articles besides English articles were excluded.

Authors, as two independent reviewers, selected the articles, extracted the data, and analyzed the data. Any discrepancies were resolved by consensus between the reviewers will be discussed. The reviewers evaluated the title for all studies that were identified through the search strategy. Irrelevant researches, opinions, recommendations, commentaries, and researches using microorganisms with a size of more than $0.072 \mu \mathrm{m}$ were excluded.

Full texts were evaluated when there was insufficient information in the title to make decisions about inclusion and exclusion or when the article title suggested the study would match the inclusion criteria established. References in reviewed articles were examined to identify studies that may not have been identified through the primary search strategy. A total of 8 full-text articles were reviewed however one article was excluded as the study only evaluated the efficacy of surgical masks (Figure 1).

The performance of a mask is evaluated by the measurement of its filtration efficiency. The filtration efficiency reflects the mask's ability to filter particulates or microorganisms. ${ }^{5}$ Filtration efficiency is evaluated by exposing the convex side of the mask to aerosols generated by a nebulizer. The detected colonies or particulates that escape the mask is then counted. The filtration efficiency can be calculated by the formula (Figure 2). ${ }^{5-7}$ The number of the particulate count when a mask is not used is subtracted with the number of the particulate count when a mask is used, divided by the number of the particulate count when a mask is not used and multiplied by $100 .{ }^{7}$

Another aspect that can be evaluated is the mask's pressure drop $(\Delta \mathrm{P})$. The pressure drop reflects how comfortable the mask is. The $\Delta \mathrm{P}$ is inversely proportional to the level of comfort-the the higher the pressure drop is, the more uncomfortable the mask is to be worn. ${ }^{5}$

Most of the studies involved in this review article are non-randomized controlled studies thus ROBINS-I Assessment of Bias in Non-randomized Studies was used. Seven parameters were presence of confounding factors, selection bias, bias in classification of intervention, bias due to deviations from intended interventions, presence of missing data, measurement bias, and bias in selection of the reported result. The study has a low risk of bias if all parameters showed low risk of bias. The study has a moderate risk of bias if some parameters show low risk and some show moderate risk of bias. The study has a serious risk of bias if at least one parameter is judged to have a serious risk of bias. The study has a critical risk of bias if at least one parameter is judged to have critical risk. Authors, as two independent researchers, assess methodological quality and standard of outcome reporting in the included studies.

\section{Results}

In the end, 5 studies that studied the filtration efficiency of cloth face mask in comparison to surgical mask against microorganisms or particles sized $\leq 0.072 \mu \mathrm{m}$ were included. The 2 journals which compared the filtration efficiency of different fabrics were also included. Studies using microorganisms $\leq 0.072 \mu \mathrm{m}$ were included as researches using the actual SARS-CoV-2 virus is still

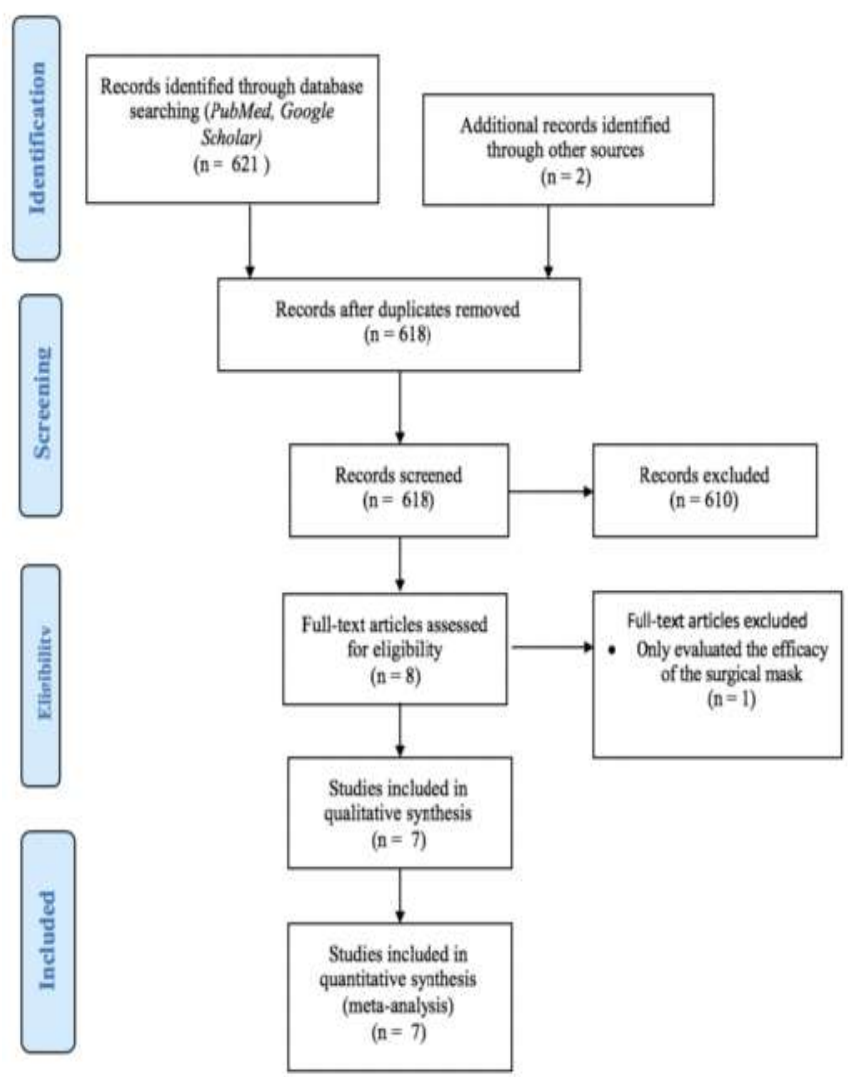

Figure 1. Systematic Flow of Literature Searching

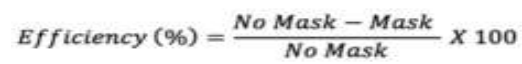

Figure 2. Filtration Efficiency5-7 
Table 1. The List of Characteristic Studies

\begin{tabular}{|c|c|c|c|c|c|}
\hline Author (Years) & Population & Method & Intervention vs Control & Result (Filtration Efficiency) & Comments \\
\hline $\begin{array}{l}\text { Davies, et al. },^{8} \\
(2013)\end{array}$ & $\begin{array}{l}8 \text { different fabrics and } \\
\text { a surgical mask were } \\
\text { used }\end{array}$ & $\begin{array}{l}\text { Filtration efficiency was evaluated } \\
\text { with aerosols of Bacteriophage } \\
\text { MS } 2(0.023 \mu \mathrm{m}) \text { and } B \text {. atrophecus } \\
(0.95-1.25 \mu \mathrm{m}) \text { generated by a } \\
\text { Collison nebulizer. }\end{array}$ & $\begin{array}{l}\text { Intervention: tea towel, } \\
\text { cotton blend, antimicrobial } \\
\text { pillowcase, linen, pillow- } \\
\text { case, silk, } 100 \% \text { cotton } \\
\text { t-shirt, scarf. } \\
\text { Control: surgical mask }\end{array}$ & $\begin{array}{l}\text { Against Bacteriophage MS2: } \\
\text { - Surgical mask: } 89.52 \% \\
\text { - Cloth face masks: } \leq 72.46 \% \\
\text { Against } \text { B. atrophecus: } \\
\text { - Surgical mask: } 96.35 \% \\
\text { - Cloth face masks: } \leq 83.24 \%\end{array}$ & - \\
\hline $\begin{array}{l}\text { Bae, et al. }{ }^{9} \\
(2020)\end{array}$ & $\begin{array}{l}4 \text { COVID-19 positive } \\
\text { patients }\end{array}$ & $\begin{array}{l}\text { Patients were asked to cough into } \\
\text { a petri dish without a mask while } \\
\text { using a surgical mask and a cloth } \\
\text { cface mask. } \\
\text { Nasopharyngeal and saliva samples } \\
\text { were obtained before patients were } \\
\text { instructed to cough. }\end{array}$ & $\begin{array}{l}\text { Intervention: cloth face } \\
\text { mask and a surgical mask } \\
\text { Control: no mask }\end{array}$ & $\begin{array}{l}\text { Both masks were ineffective. } \\
\text { However, cloth face masks } \\
\text { filtered SARS-CoV-2 better } \\
\text { than surgical masks. }\end{array}$ & $\begin{array}{l}\text { The confounding } \\
\text { factor was not } \\
\text { controlled }\end{array}$ \\
\hline $\begin{array}{l}\text { Neupane, et al., } 6 \\
(2019)\end{array}$ & $\begin{array}{l}\text { Petri dishes with a } \\
\text { microscope overslips } \\
\text { contained inside were } \\
\text { covered with four } \\
\text { different cloth face } \\
\text { masks, one surgical } \\
\text { mask, and no mask }\end{array}$ & $\begin{array}{l}\text { The apparatus was kept } 20 \text { feet } \\
\text { above ground in central Kathmandu } \\
\text { for } 30 \text { minutes. } \\
\text { Microscope magnification of } 100 x \\
\text { was used to evaluate the number of } \\
\text { particles deposited. }\end{array}$ & $\begin{array}{l}\text { Intervention: petri dish } \\
\text { covered by cloth face } \\
\text { mask and a surgical mask } \\
\text { Control: Petri dish without } \\
\text { a mask }\end{array}$ & $\begin{array}{l}\text { Against particles sized } \leq 10 \mu \mathrm{m} \\
\text { Cloth face mask: } 63-84 \% \\
\text { Surgical mask: } 94 \%\end{array}$ & $\begin{array}{l}\text { Selection bias } \\
\text { may occur }\end{array}$ \\
\hline $\begin{array}{l}\text { Ma, et al., }{ }^{10} \\
(2020)\end{array}$ & $\begin{array}{l}\text { A surgical mask, an N95 } \\
\text { mask, and a polyester } \\
\text { mask with four layers of } \\
\text { kitchen paper added to } \\
\text { it were involved. }\end{array}$ & $\begin{array}{l}\text { Avian influenza was incorporated } \\
\text { into a Type } 403 \text { nebulizer and } \\
\text { aerosols were produced to } \\
\text { challenge masks involved. }\end{array}$ & $\begin{array}{l}\text { Intervention: surgical mask } \\
\text { and polyester mask with } \\
\text { four layers of kitchen paper } \\
\text { Control: N95 mask }\end{array}$ & $\begin{array}{l}\text { Medical mask: } 97.14 \% \\
\text { Polyester mask with four layers } \\
\text { of kitchen paper: } 95.15 \% \\
\text { N95 Mask: } 99.98 \%\end{array}$ & Low risk of bias \\
\hline $\begin{array}{l}\text { Shakya, et al., }{ }^{7} \\
(2017)\end{array}$ & $\begin{array}{l}3 \text { cloth face masks, } \\
1 \text { surgical mask, and } \\
2 \text { N95 masks were } \\
\text { involved in this study }\end{array}$ & $\begin{array}{l}\text { Polystyrene latex (PSL) was used } \\
\text { to generate aerosols with a flow } \\
\text { rate of } 8 \text { and } 19 \text { Liter per minute } \\
\text { (LPM) to challenge masks involved. } \\
\text { Masks were placed on a mannequin } \\
\text { and attached to an aerodynamic } \\
\text { particulate sizer (APS) and scanning } \\
\text { mobility particle sizer (SMPS) which } \\
\text { accurately count the amount and } \\
\text { sizes of particles that penetrate the } \\
\text { mask. }\end{array}$ & $\begin{array}{l}\text { Intervention: cloth face } \\
\text { masks, surgical masks } \\
\text { Control: N95 Mask }\end{array}$ & $\begin{array}{l}\text { Against particles 30-100 nm, } \\
8 \text { Liter per minute (LPM) } \\
\text { - Simple Mask (SM): 86-93\% } \\
\text { - Cloth Mask (CM) 1: 82-90\% } \\
\text { - Cloth Mask (CM)2: 63-65\% } \\
\text { - Cloth Mask (CM) 3: 50-55\% } \\
\text { - N95 1: 85-97\% } \\
\text { - N95 2: } \sim 65-85 \% \\
\text { Against particles 30-100 nm, } \\
\text { 19 LPM } \\
\text { - Simple Mask (SM): } ~ 60-65 \% \\
\text { - Cloth Mask (CM) 1: 75-82\% } \\
\text { - Cloth Mask (CM)2: 10-30\% } \\
\text { - Cloth Mask (CM)3: 22-28\% } \\
\text { - N95 1: } ~ 80-90 \% \\
\text { - N95 2: 75-85\% }\end{array}$ & Low risk of bias \\
\hline
\end{tabular}

scarce at the time being. A cut off of $0.072 \mu \mathrm{m}$ was made due to the size of SARS-CoV-2. The results of the included articles are summarized in Table 1.

ROBINS-I Assessment of Bias in Non-randomized Studies was used to measure the risk of bias in this review. Two independent authors assessed methodological quality and standard of outcome report in the included studies. The results of the assessment of the studies were presented in Table 2.

The filtration efficiency of cloth face masks differs from one another due to the different fabric materials used. Table 3 summarizes filtration efficiency and pressure drop of common fabrics studied in research by Davies, et al., ${ }^{8} \mathrm{Ma}$, et al., ${ }^{10}$ and Rengasamy, et al. ${ }^{11}$

Davies, et al., ${ }^{8}$ measured the filtration efficiency of each fabric by challenging the different types of fabrics with aerosols of Bacteriophage MS2 $(0.023 \mu \mathrm{m})$ and $B$. atrophecus $(0.95-1.25 \mu \mathrm{m})$ generated by a Collison nebulizer. The filtration efficiency listed in table 3 is the fabric's efficiency in filtering Bacteriophage MS2. Ma, et al., ${ }^{10}$ challenged the cloth face mask using avian influenza, whereas Rengasamy, et al., ${ }^{11}$ (Table 4) challenged the fabrics using aerosols of sodium chloride sized 20 $1,000 \mathrm{~nm}$. Rengasamy, et al., ${ }^{11}$ counted the penetration percentage of the fabrics instead of its filtration efficiency. Penetration percentage was determined as "the ratio of particle concentration downstream to upstream multiplied by $100 " .11$

\section{Discussion}

It can be concluded that most studies found that surgical masks have higher filtration efficiency compared to a cloth face mask. $6,8,10$ Studies by Bae, et al., ${ }^{9}$ and Shakya, et al., ${ }^{7}$ show that a cloth face mask can be more 
Table 2. ROBINS-I Assessment of Bias in Non-Randomized Studies

\begin{tabular}{|c|c|c|c|c|c|c|}
\hline & Bae, et al.,$^{9}$ & Davies, et al.,$^{8}$ & Ma, et al.,10 & Neupane, et al., 6 & Shakya, et al. ${ }^{7}$ & Rengasamy, et al.,11 \\
\hline \multicolumn{7}{|l|}{ Bias due to: } \\
\hline Confounding & Serious & Low & Low & Serious & Low & Serious \\
\hline $\begin{array}{l}\text { Selection of participants in } \\
\text { the study }\end{array}$ & Low & No information & Low & Critical & Low & Low \\
\hline $\begin{array}{l}\text { Deviations from intended } \\
\text { interventions }\end{array}$ & Low & Low & Low & Low & Low & Low \\
\hline Missing data & Low & Low & Low & Low & Low & Low \\
\hline \multicolumn{7}{|l|}{ Bias in: } \\
\hline Measurement outcomes & Low & Low & Low & Low & Low & Low \\
\hline Selection of the reported result & Low & Low & Low & Low & Low & Low \\
\hline Overall judgement & Serious risk of bias & No information & Low risk of bias & Critical risk of bias & Low risk of bias & Serious risk of bias \\
\hline
\end{tabular}

Table 3. Filtration Efficiency of Common Fabrics used as Masks

\begin{tabular}{llcr}
\hline Study & Fabric Used as Mask & Filtration Efficiency & $(\boldsymbol{\Delta P})$ \\
\hline Davies, et al., ${ }^{8}$ & Tea towel & $72.46 \%$ & 7.23 \\
& Cotton blend & $70.24 \%$ & 6.18 \\
& Antimicrobial pillowcase & $68.9 \%$ & 6.11 \\
& Linen & $61.67 \%$ & 4.5 \\
& Pillowcase & $57.13 \%$ & 3.88 \\
& Silk & $54.32 \%$ & 4.57 \\
& 100\% cotton t-shirt & $50.85 \%$ & 4.29 \\
Ma, et al., 10 & Scarf & $48.87 \%$ & 4.36 \\
& Polyester cloth with 4 layers & & \\
& of kitchen paper & $95 \%$ & N/A \\
\hline
\end{tabular}

Note: $\Delta \mathrm{P}$ : pressure drop

effective compared to a surgical mask. The study by Bae, et al., ${ }^{9}$ did not control confounding factors, such as mask leakage, and therefore may intervene with results.

A cloth face mask may be inferior to a surgical mask due to the average size of its pores. Cloth face mask generally has larger pores compared to surgical masks, therefore allowing more particles and micro-organisms to penetrate. However, the study by Neupane, et al.,${ }^{6}$ only studied the pore size of 20 different masks and these masks were chosen based on its fabric and material, and may not represent cloth face masks entirely.

It must also be noted that the filtration efficiency of each cloth face masks differs from one mask to another. 6,7 This depends on the mask's fabric material. ${ }^{8,11}$ Filtration efficiency of both surgical mask and cloth face mask also decreases as the masks are challenged by smaller microorganisms as shown by studies by Davies, et al., ${ }^{8}$ and Shakya, et al.. ${ }^{7}$ The study by Davies, et al.,8 involved 21 volunteers who were asked to cough using no mask, a surgical mask and a homemade mask into a cough box where an Andersen sampler and settle plates are placed inside. The study reported that the number of colonyforming units increased as the particle size decreased.

A homemade mask can also decrease the expulsion of microorganisms compared to not using any mask. These differences were seen as protective for particles less than
Table 4. Penetration Level of Mask Type and Fabrics used as Masks, ${ }^{11}$

\begin{tabular}{|c|c|c|}
\hline Mask Type and Fabric Used & $\begin{array}{l}\text { Penetration Against } \\
\text { NACl Particles Size } \\
20 \mathrm{~nm}\end{array}$ & $(\Delta \mathbf{P})$ \\
\hline \multicolumn{3}{|l|}{ 'Respro' } \\
\hline Bandit mask (fiber composition N/A) & $60 \%$ & N/A \\
\hline \multicolumn{3}{|l|}{ 'Breathe health' } \\
\hline Cloth face mask (fiber composition N/A) & $70 \%$ & N/A \\
\hline Fleece mask (fiber composition N/A) & $40 \%$ & N/A \\
\hline \multicolumn{3}{|l|}{ Sweatshirt } \\
\hline $85 \%$ cotton and $15 \%$ polyester & $48 \%$ & N/A \\
\hline $70 \%$ cotton and $30 \%$ polyester & $\sim 30 \%$ & N/A \\
\hline $60 \%$ cotton and $40 \%$ polyester & $60 \%$ & N/A \\
\hline \multicolumn{3}{|l|}{ T-shirt } \\
\hline $99 \%$ Cotton and $1 \%$ polyester & $\sim 82 \%$ & N/A \\
\hline $100 \%$ Cotton & $\sim 75 \%$ & $\mathrm{~N} / \mathrm{A}$ \\
\hline $60 \%$ Cotton and $40 \%$ polyester & $\sim 58 \%$ & N/A \\
\hline \multicolumn{3}{|l|}{ Scarf } \\
\hline $100 \%$ Cotton & $70-75 \%$ & N/A \\
\hline $100 \%$ Polyester & $10 \%$ & N/A \\
\hline
\end{tabular}

Note: $\Delta \mathrm{P}$ : pressure drop

3.3 micrometers. Several kinds of cloth face masks were as good and as effective as surgical masks in the efficiency of filtrating particles more than 1 micrometer. ${ }^{8}$

Although surgical masks are concluded to be more effective than cloth face masks, it must be noted that neither surgical masks nor cloth face masks have a filtration efficiency that reaches $100 \%$, especially for particles or microorganisms sized $<0.072 \mu \mathrm{m} .6-10,12$ It must also be kept in mind that although cloth face mask has lower filtration efficiency, it still aids in filtering particles and microorganisms and is better than not wearing a mask at all.9,13 Therefore wearing a cloth face mask should not be deemed as useless.

Judging from its filtration efficiency, polyester is concluded to be the best fabric that can be used as a mask. $\mathrm{Ma}$, et al., 10 found that adding four layers of kitchen paper onto a polyester face mask results in a filtration efficiency as high as $95 \%$. This is supported by the result found by Rengasamy, et al., ${ }^{11}$ where scarf made of $100 \%$ polyester has a penetration percentage of $10 \%$. Sweatshirts and shirts made of polyesters also have lower 
penetration percentage. The concentration of polyester seems to be inversely proportional to the penetration percentage. However, none of the articles reviewed in this article studied the pressure drop of masks made of polyester, therefore whether the mask is comfortable or not is unknown.

Although tea towels have the second-highest filtration efficiency (72.46\%), the high-pressure drop (7.23) indicates discomfort when using this as a mask. Discomfort may cause users to be noncompliant and therefore reduces the efficacy of the mask itself. As a comparison, surgical masks have a pressure drop of 5.23 and is considered comfortable when being worn. ${ }^{8}$

Therefore, an alternative to polyester mask is using a mask made of cotton blend. The cotton blend has a filtration efficiency of $70.24 \%$ and a pressure drop of 6.18 . In comparison to surgical masks, this mask may be more uncomfortable but it is still significantly lower than the amount of pressure drop tea towels have. ${ }^{8}$ It is speculated that the cotton blend provides decent filtration efficiency in comparison to other fabrics as the combination of cotton and other materials provide mechanical filtration and electrostatic-based filtration. ${ }^{14}$

ROBINS-I was used to evaluate the presence of bias in each journal (Table 1). Although bias is nearly impossible to avoid, unfortunately, most of the studies included had a high risk of bias. Out of six studies included in this review, one did not have enough information, two had a serious risk of bias, one had a critical risk of bias and two had a low risk of bias that could affect the results. More studies regarding the efficacy of cloth face mask and the filtration efficiency of each fabric should be made shortly. More reviews should also be made for better understanding.

In April 3, 2020, CDC recommended the use of cloth face masks in public settings where physical distancing is difficult to conduct. These settings include markets and pharmacies. The rationale behind this recommendation is possible virus transmission by COVID-19 positive patients who are asymptomatic or pre-symptomatic and shortages of N95 respirator and surgical masks.

These recommendations intend to slow down COVID-19 transmission, especially from people who are asymptomatic or pre-symptomatic as they may not be aware that they are infectious. These recommendations also intend to prevent further shortages of N95 respirators and surgical masks to allow these PPEs to be prioritized for healthcare workers. Regardless of this new recommendation, other measures, such as physical distancing and practicing good hand hygiene, must also be practiced. 4

In April 6, 2020, WHO published its interim guidance on the use of masks in the context of COVID-19. In this interim guidance, it could be highlighted that WHO re- mains neutral in the context of public mask-wearing and the use of cloth face mask.

This interim guidance stated that the efficacy of nonmedical masks (e.g., cloth face masks) was not well evaluated, therefore no recommendation for or against the use of non-medical masks was made by WHO. The WHO suggested certain things be taken into consideration if individuals were to decide to use cloth face masks, such as the number of layers of fabric or tissue, breathability, water repellence, the shape of the mask, and fit of the mask. ${ }^{15}$

\section{Conclusion}

All of the previous studies reviewed in this research showed the same result that cloth face masks remain inferior compared to surgical or medical masks. However, although in terms of efficacy it is inferior, it must be noted that cloth face masks still do filter viruses and could not be deemed as useless. Cloth face mask's filtration efficiency depends on its material and this review concludes that mask made of polyester seems to be the most effective. Neither cloth face masks nor surgical masks provide $100 \%$ filtration efficiency, thus other measures, such as physical distancing, practicing good hand hygiene, and disinfecting, must also be done in combination to reduce transmission.

\begin{abstract}
Abbreviations
COVID-19: Coronavirus Disease 2019; MeSH: Medical Subject Headings of the National Library of Medicine; CFR: Case Fatality Rate; CPR: Cardiopulmonary Resuscitation; WHO: World Health Organization; PPE: Personal Protective Equipment; CDC: Centers of Disease Control; PSL: Polystyrene Latex; APS: Aerodynamic Particulate Sizer; LPM: Liters Per Minute, SMPS: Scanning Mobility Particle Sizer SM: Simple Mask; CM: Cloth mask.
\end{abstract}

\section{Ethics Approval and Consent to Participate}

No ethics approval was requested/attached as this review article that did not involve any subjects.

\section{Competing Interest}

The authors declare that there are no competing interests.

\section{Availability of Data and Materials}

Data included in this article are openly available and may be accessed by accessing the links attached in the reference section.

\section{Authors' Contribution}

Saraswati Anindita Rizki contributed to the collection of studies, assessing the qualities of studies included in this article using the ROBINS-I assessment and drafted the article. Andre Kurniawan contributed to the collection of studies, assessing the qualities of studies included using ROBINS-I and critically reviewed the draft of this article. The final version was approved by all authors. 


\section{Acknowledgment}

The authors would like to thank everyone who helped us in this review.

\section{References}

1. World Health Organization. WHO coronavirus disease (COVID-19) dashboard; 2020 [updated 2020 May 26; cited 2020 May 27].

2. World Health Organization. Modes of transmission of virus causing COVID-19: implications for IPC precaution recommendations; 2020 [updated 2020 Mar 29; cited 2020 Apr 4].

3. Cowling BJ, Ali ST, Ng TWY, Tsang TK, Li JCM, Fong MW, et al. Impact assessment of non-pharmaceutical interventions against coronavirus disease 2019 and influenza in hong kong: an observational study. Lancet Public Health. 2020; 5 (5): e279-88.

4. Centers for Disease Control and Prevention. Considerations for wearing cloth face coverings: help slow the spread of COVID-19. 2020 [updated 2020 Apr 3; cited 2020 Apr 10].

5. Shokri A, Golbabaei F, Zadeh AS, Baneshi MR, Asgarkashani N, Zarandi AF. Evaluation of physical characteristics and particulate filtration efficiency of surgical masks used in Iran's hospitals. International Journal of Occupational Hygiene. 2015; 7 (1): 10-6.

6. Neupane BB, Mainali S, Sharma A, Giri B. Optical microscopic study of surface morphology and filtering efficiency of face masks. PeerJ-Life \& Environmental. 2019; 7: e7142.

7. Shakya KM, Noyes A, Kallin R, Peltier RE. Evaluating the efficacy of cloth facemasks in reducing particulate matter exposure. Journal of Exposure Science \& Environmental Epidemiology. 2017; 27: 352-7.

8. Davies A, Thompson KA, Giri K, Kafatos G, Walker J, Bennett A.
Testing the efficacy of homemade masks: would they protect in an influenza pandemic?. Disaster Medicine and Public Health Preparedness. 2013; 7 (4): 413-8.

9. Bae S, Kim M-C, Kim JY, Cha H-H, Lim JS, Jung J, et al. Effectiveness of surgical and cotton masks in blocking SARS-CoV-2: a controlled comparison in 4 patients. Annals of Internal Medicine. 2020; 173 (1): W22-3.

10. Qing-Xia M, Hu Shan, Hong-Liang Z, Gui-Mei L, Rui-Mei Y, JiMing C. Potential utilities of mask-wearing and instant hand hygiene for fighting SARS-COV-2. Journal of Medical Virology. 2020; 1-5.

11. Rengasamy S, Eimer B, Shaffer RE. Simple respiratory protection evaluation of the filtration performance of cloth masks and common fabric materials against 20-1000 nm size particles. The Annals of Occupational Hygiene. 2010; 54 (7): 789-98.

12. MacIntyre CR, Seale H, Dung TC, Hien NT, Nga PT, Chughtai AA, et al. A cluster-randomized trial of cloth masks compared with medical masks in healthcare workers. BMJ Open. 2015; 5 (4): 1-10.

13. Clase CM, Fu EL, Joseph M, Beale RCL. Cloth masks may prevent transmission of COVID-19: an evidence-based, risk-based approach. Annals of Internal Medicine. 2020; M20-2567.

14. Konda A, Prakash A, Moss GA, Schmoldt M, Grant GD, Guha S. Aerosol filtration efficiency of common fabrics used in respiratory cloth masks. ACS Nano. 2020; 14: 6339-47.

15. World Health Organization. Advice on the use of masks in the community, during home care, and in health care settings in the context of the novel coronavirus (2019-nCov) outbreak: interim guidance, 29 January 2020; 2020 [updated 2020 Apr 6; cited 2020 Apr 8]. 